\title{
The Effect of the Number of Fibers in Hollow Fiber Membrane Modules for $\mathrm{NO}_{\mathrm{x}}$ Absorption
}

\author{
Sutrasno Kartohardjono ${ }^{1 *}$, Mohamad Sofwan Rizky1 ${ }^{1}$ Eva Fathul Karamah ${ }^{1}$, Woei-Jye Lau ${ }^{2}$ \\ ${ }^{1}$ Department of Chemical Engineering, Faculty of Engineering, Universitas Indonesia, Kampus UI Depok, \\ Depok 16424, Indonesia \\ ${ }^{2}$ Advanced Membrane Technology Research Centre, Universiti Teknologi Malaysia, 81310 Skudai, Johor, \\ Malaysia
}

\begin{abstract}
As a type of gas that contributes to air pollution, nitrogen oxide $\left(\mathrm{NO}_{\mathrm{x}}\right)$ has harmful effects on humans and the environment. Among several types of $\mathrm{NO}_{\mathrm{x}}$, nitric oxide (NO) and nitrogen dioxide $\left(\mathrm{NO}_{2}\right)$ are most commonly found in air. The utilization of membranes as reactors is a system that combines chemical reactions with the separation process through membranes to increase the conversion of the reaction. This study investigated the absorption process by utilizing a hollow fiber membrane module (polysulfone) as a bubble reactor with $\mathrm{H}_{2} \mathrm{O}_{2}\left(0.5\right.$ wt.\%) and $\mathrm{HNO}_{3}(0.5 \mathrm{M})$ as the absorbent. NOx feed gas was flown into the tube side of the membrane; the shell side was filled with static $\mathrm{H}_{2} \mathrm{O}_{2}$ and $\mathrm{HNO}_{3}$ and the shell input and the tube output flow were closed to create gas bubbles. The experimental results showed that the absorption efficiency increased, but the mass transfer coefficient and flux decreased as the number of fibers in the membrane module increased at the same feed gas flow rate. The $\mathrm{NO}_{\mathrm{x}}$ loading is relatively constant as the amount of fiber in the membrane module increased at the same feed gas flow rate. The experimental results also showed that the mass transfer coefficient, flux, and $\mathrm{NO}_{\mathrm{x}}$ loading increased with increasing feed gas flow rate, but the absorption efficiency decreased when using the same number of fibers in the membrane module. The maximum $\mathrm{NO}_{\mathrm{x}}$ absorption efficiency achieved in this study was $94.6 \%$ at the feed gas flow rate of $0.1 \mathrm{~L} / \mathrm{min}$, using a membrane module with 48 fibers.
\end{abstract}

Keywords: Absorption efficiency; Hollow fiber; Mass transfer coefficient; $\mathrm{NO}_{\mathrm{x}}$ loading

\section{Introduction}

Currently, atmospheric pollution is a significant problem across the globe; apart from $\mathrm{SO}_{2}$, the most dangerous and toxic gas is $\mathrm{NO}_{\mathrm{x}}$ (nitrogen oxide). $\mathrm{NO}_{\mathrm{x}}$ is produced from the reaction between nitrogen $(\mathrm{N})$ and oxygen $(\mathrm{O})$ during the combustion process at high temperatures. Among several types of $\mathrm{NO}_{\mathrm{x}}$, such as $\mathrm{N}_{2} \mathrm{O}$, nitrogen monoxide (NO), $\mathrm{N}_{2} \mathrm{O}_{3}$, nitrogen dioxide $\left(\mathrm{NO}_{2}\right), \mathrm{N}_{2} \mathrm{O}_{4}$, and $\mathrm{N}_{2} \mathrm{O}_{5}, \mathrm{NO}$ and $\mathrm{NO}_{2}$ are the ones most often found in atmospheric air, with NO comprising $>90 \%$ of the total amount of gas (Kumar et al., 2015). Furthermore, $49 \%$ of $\mathrm{NO}_{\mathrm{x}}$ comes from motor vehicles, $27 \%$ comes from the activities of the electricity generation industry, and $19 \%$ comes from household activities. $\mathrm{NO}_{\mathrm{x}}$ has also been reported to have the ability to cause acid rain, form fog fumes, decrease water quality, destroy ecosystems, and contribute to global warming (Choi et al., 2014; Gao et al., 2018; Kartohardjono et al., 2019a; Sun et al., 2019). In addition, $\mathrm{NO}_{\mathrm{x}}$ is also having harmful effect on the human being (Kartohardjono et al., 2019b). 
The reduction of $\mathrm{NO}_{\mathrm{x}}$ in exhaust gases, such as those from boilers and the nitric acid $\left(\mathrm{HNO}_{3}\right)$ industry, is currently attracting much attention due to increasingly stringent environmental regulations; for example, the annual average quality standard for $\mathrm{NO}_{2}$ in ambient air is set at $0.053 \mathrm{ppm}$ (Indonesia, 1999). Several technologies have been pioneered for this purpose, including Selective Catalytic Reduction, Selective Non-Catalytic Reduction, adsorption, and absorption using column contactors (Kartohardjono et al., 2019b). Similarly, the absorption of $\mathrm{NO}_{\mathrm{x}}$ using membrane technology has also been developed; in this type of system, the contactors offer several advantages: a continuous process that is easy to operate, low energy consumption, easy scale-up, low separation costs, and the ability to produce high-quality products (Kartohardjono et al., 2017)

Hollow fiber membrane contactors have been widely used as gas-liquid contactors due to the large ratio between their surface area for contact and the equipment volume (Lipnizki and Field, 2001). Furthermore, gas absorption through the membrane contactor also the integrates separation and absorption processes to exploit the benefits of both. Moreover, the hollow fiber membrane module has two different spaces for each fluid, shell, and tube. The in-flowing liquid provides selective absorption to certain gas species, while the porous membrane acts as the contacting interface between the liquid and gas phases, allowing the unidirectional transport of gas into the liquid. For example, the gas component to be removed is absorbed into the solution when the gas stream contacts with the liquid (Wang and $\mathrm{Yu}, 2017$ ). The hollow fiber membrane module also provides a large ratio of surface area to volume, which is very beneficial for gas-liquid contact (Anggraini et al., 2019). Additionally, the mass transfer between phases that occurs in membrane modules is driven by differences in the concentration of the inter-phase components and pressure drops.

In contrast, the use of membranes as reactors involves the combination of chemical reactions with the separation process through membranes with the usual intention of increasing the conversion of the reaction. A bubble reactor is a type of reactor that is in two phases of gas and liquid; it is a cylindrical vessel with a gas distributor (sparger) at the bottom. The fluid in the gas phase flows into the vessel and, in the process, gas bubbles are formed and move through the liquid inside the vessel. The advantages of this type of reactor include high mass transfer rates, high density, and low operating and maintenance costs (Shaikh and Al-Dahhan, 2013). Bubble reactors are widely applied in chemical, petrochemical, biochemical, metallurgical, and materials industries.

A number of studies have investigated the use of membranes as additional units in processes involving bubble reactors or columns. Xia et al. (2013) immersed a hollow fiber membrane module in a liquid cylindrical bubble column reactor to test the hydrodynamic effect induced by an installed sparger. Moreover, Adewuyi et al. (2014) investigated if a membrane could remove the remaining moisture from the results of $\mathrm{NO}_{\mathrm{x}}$ gas absorption using $\mathrm{Na}_{2} \mathrm{~S}_{2} \mathrm{O}_{8}$ solvents from a bubble reactor made from glass. The present study was conducted to examine the utilization of hollow fiber membrane modules to reduce $\mathrm{NO}_{\mathrm{x}}$ from gas mixtures using a mixture of hydrogen peroxide $\left(\mathrm{H}_{2} \mathrm{O}_{2}\right)$ and $\mathrm{HNO}_{3}$ as the absorbent. It was expected that the fibers in the membrane module would increase the contact area between $\mathrm{NO}_{\mathrm{x}}$ and the absorbent solution to enhance the $\mathrm{NO}_{\mathrm{x}}$ absorption.

\section{Materials and Methods}

\subsection{Materials}

The schematic diagram of $\mathrm{NO}_{\mathrm{x}}$ absorption using a hollow fiber membrane module with the bubble reactor principle is shown in Figure 1. The modules used in this study were supplied by PT GDP Filter Bandung. The following modules were used: 16, 32, and 48 fibers, 
each with a $4 \mathrm{~cm}$ diameter and a $25 \mathrm{~cm}$ length. Moreover, the feed gas $\left(\mathrm{NO}_{\mathrm{x}}=600 \mathrm{ppm}\right)$, $\mathrm{HNO}_{3}$, and $\mathrm{H}_{2} \mathrm{O}_{2}$ were purchased from Energy Indogas Nusantara Indonesia and Merck Indonesia, respectively. The outer diameter of the polysulfone-based fibers was $2 \mathrm{~mm}$ and the inner diameter was $1.8 \mathrm{~mm}$.

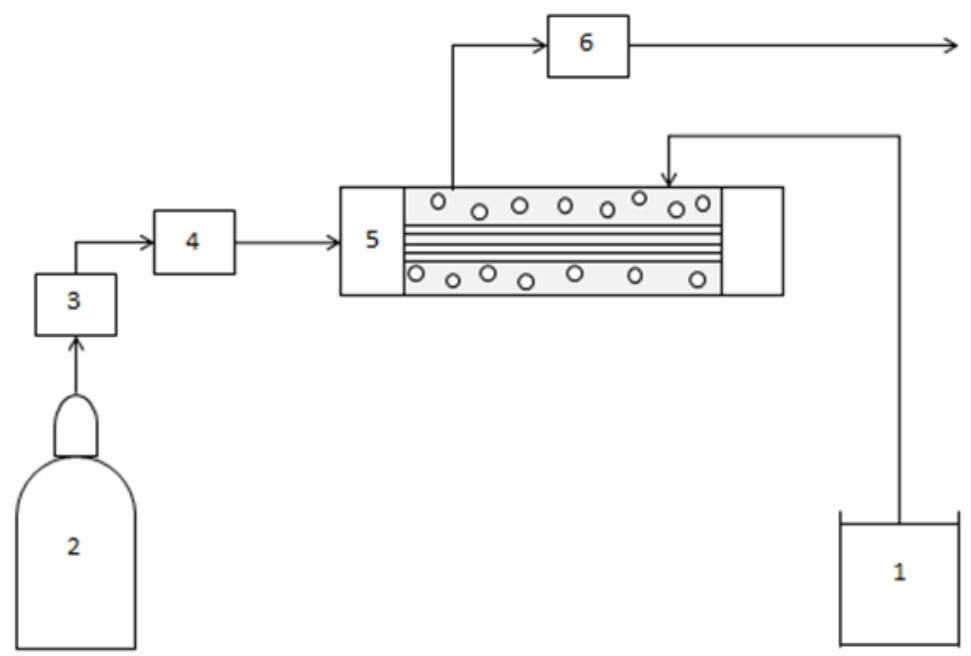

Figure 1 Schematic diagram of the experiment: (1) Absorbent tank; (2) $\mathrm{NO}_{\mathrm{x}}$ feed gas; (3) Mass flow controller; (4) Gas analyzer; (5) Hollow fiber membrane module; (6) Gas analyser

\subsection{Methods}

As shown in Figure 1, the $\mathrm{NO}_{\mathrm{x}}$ feed gas was flown into the lumen side of the membrane fibers; the shell side was filled with the static absorbent, which was a mixture of $\mathrm{HNO}_{3} 0.5 \mathrm{M}$ and $\mathrm{H}_{2} \mathrm{O}_{2} \quad 0.5 \% \mathrm{w} / \mathrm{t}$ at $1: 1$. The feed gas containing $\mathrm{NO}_{\mathrm{x}}$ of about $600 \mathrm{ppm}$ at a given flow rate penetrated the membrane fibers and created bubbles on the surface of the fiber in contact with the absorbent liquid in the shell side of the membrane module. The gas moved to the surface of the absorbent solution in the membrane module and exited through the top of the module, where the $\mathrm{NO}_{\mathrm{x}}$ concentration and gas flow rate were measured. Furthermore, the inlet and outlet gas compositions to and from the membrane contactor were analyzed using the ECOM-D Combustion Gas Analyzer; the flow rates were measured using a mass flow meter (Shanghai Cixi Instruments). The independent variables used in this study were the number of membrane fibers, which were 16,32 , and 48 , and the feed gas flow rates of $0.1,0.125,0.15,0.175$, and $0.2 \mathrm{~L} / \mathrm{min}$.

The amount of $\mathrm{NO}_{\mathrm{x}}$ absorbed $\left(\mathrm{NO}_{\mathrm{x}}\right.$ abs) by the absorbent and the absorption efficiency, $R$, from the experiment were calculated using Equation 1 and Equation 2, respectively.

$$
\begin{aligned}
& N O x_{A b s}=\left(x_{i} F_{i}-x_{o} F_{O}\right) \frac{P}{R T} \\
& R=\frac{N O x_{A b s}}{x_{i} F_{i}} x 100 \%
\end{aligned}
$$

The mass transfer coefficient, $K_{\mathrm{G}}$, flux, $J$, and $\mathrm{NO}_{\mathrm{x}}$ loading were calculated using Equations 3, 4, and 5, respectively.

$$
\begin{aligned}
& K_{G}=\frac{Q_{G}}{A} \ln \left(\frac{x_{i}}{x_{o}}\right) \\
& J=\frac{N O x_{A b s}}{A} \\
& N O x_{\text {Loading }}=\frac{N O x_{A b s}}{n_{\text {Absorbent }}}
\end{aligned}
$$


where $x \mathrm{i}$ and $F_{\mathrm{i}}$ and $x_{\mathrm{o}}$ and $F_{\mathrm{o}}$ are the $\mathrm{NO}_{\mathrm{x}}$ concentration and flow rate in the inlet and outlet membrane module, respectively. $P, T$, and $R$ are the pressure, temperature, and gas constant, respectively. $Q_{\mathrm{G}}, \mathrm{A}$, and $n_{\mathrm{absorbent}}$ are the feed gas flow rate, membrane fibers surface area, and absorbent mole, respectively.

\section{Results and Discussion}

Absorption tests were used to investigate the effects of the number of membrane fibers and the feed gas flow rate on $\mathrm{NO}_{\mathrm{x}}$ absorption efficiency, mass transfer coefficient, mass transfer flux, and $\mathrm{NO}_{\mathrm{x}}$ loading. The absorption percentage, $R$, is a parameter that describes how much $\mathrm{NO}_{\mathrm{x}}$ is absorbed in comparison to the initial amount of $\mathrm{NO}_{\mathrm{x}}$. As seen in Figure 2, the $\mathrm{NO}_{\mathrm{x}}$ absorption efficiency increases as the number of fibers in the membrane module increases at the same feed gas flow rate. However, the $\mathrm{NO}_{\mathrm{x}}$ absorption efficiency decreases with the increase in the feed gas flow rate when the number of fibers in the membrane module is the same. The increasing number of membrane fibers caused the percentage of $\mathrm{NO}_{\mathrm{x}}$ absorption to increase due to the higher surface-to-volume ratio; this indicates that the amount of contact between the gas-liquid phases increases at the same volume so it enhances the amount of $\mathrm{NO}_{\mathrm{x}}$ absorbed by the absorbent solution in the membrane module. In this study, the $\mathrm{NO}_{\mathrm{x}}$ absorption efficiency increased by $0.4 \%$ from $94.2 \%$ to $94.6 \%$ when the number of fibers in the membrane module increased from 16 to 48 at the feed gas flow rate of $0.1 \mathrm{~L} / \mathrm{min}$. The increase was insignificant because the absorption efficiency was already high in the membrane module with the lowest number of fibers. The same trend was reported by Wang and Yu (2017) in a study that used a hollow fiber polypropylene membrane contactor to reduce the $\mathrm{NO}_{\mathrm{x}}$ gas content with a feed gas composition of 184.8 $\mathrm{ppm}$ and a gas flow rate of $100 \mathrm{~mL} / \mathrm{min}$. They used a solvent that was a mixture of water with $\mathrm{H}_{2} \mathrm{O}_{2} 0.2 \% \mathrm{w} / \mathrm{t}$ and $\mathrm{NaCl} 5 \% \mathrm{w} / \mathrm{t}$. The feed gas flow rate ranged from 0.05 to $0.25 \mathrm{~L} / \mathrm{min}$ at a temperature of $323 \mathrm{~K}$. In the present study, the highest absorption efficiency was $94.6 \%$ at $0.1 \mathrm{~L} / \mathrm{min}$ gas flow rate, with a membrane module with 48 fibers, while Wang and Yu (2017) stated the maximum absorption in hydrophobic polypropylene hollow fiber membrane modules with 3000 fibers was $\sim 92 \%$ at a $0.05 \mathrm{~L} / \mathrm{min}$ feed gas flow rate. However, in a wet process of oxidation-absorption in a bubble reactor, the maximum conversion was found to be as high as $94.5 \%$ using $\mathrm{Na}_{2} \mathrm{~S}_{2} \mathrm{O}_{8}$ and $\mathrm{CaO}_{2}$ as the oxidants to remove 345 ppm $\mathrm{NO}_{\mathrm{x}}$ with a feed gas flow rate of $2 \mathrm{~L} / \mathrm{min}$ (Wang et al., 2018).

An increase in the feed gas flow rate can increase the amount of $\mathrm{NO}_{\mathrm{X}}$ absorbed. Thus, based on Equation 2 this can increase the absorption efficiency. However, based on Equation 2 an increase in the feed gas flow rate can also reduce the absorption efficiency. The decrease in absorption efficiency caused by increasing the feed gas flow rate indicates that the amount of $\mathrm{NO}_{\mathrm{x}}$ present in the feed gas is has a greater effect than increasing the amount of $\mathrm{NO}_{\mathrm{x}}$ absorbed (Kartohardjono et al., 2019b). In the present study, the highest $\mathrm{NO}_{\mathrm{x}}$ absorption efficiency achieved was $94.6 \%$ at the feed gas flow rate of $0.1 \mathrm{~L} / \mathrm{min}$ when the number of fibers in the contactor was 48. Furthermore, the mass transfer process consisted of three consecutive steps: (i) diffusion from the bulk gas phase to the outer surface of the membrane; (ii) diffusion through the membrane pores; and (iii) dissolution into the absorption liquid and liquid phase diffusion/chemical reaction (Kartohardjono et al., 2019c). In this case, the increase in the gas flow rate reduced the residence time of the gas so as to reduce the contact time between the gas and the membrane module; consequently, this made it possible for the incoming feed gas to not be absorbed into the membrane module (shell-side bypass). In the present study, the $\mathrm{NO}_{\mathrm{x}}$ absorption efficiency was decreased by $0.6 \%$ from $94.6 \%$ to $94.0 \%$ when the feed gas flow rate increased from 0.1 to $0.2 \mathrm{~L} / \mathrm{min}$. The efficiency of $\mathrm{NO}_{\mathrm{x}}$ absorption in this study was already high, at around 
93.8\%, even in the membrane module with the lowest number of fibers (16 fibers) and at the highest feed gas flow rate $(0.2 \mathrm{~L} / \mathrm{min})$, as shown in Figure 2.

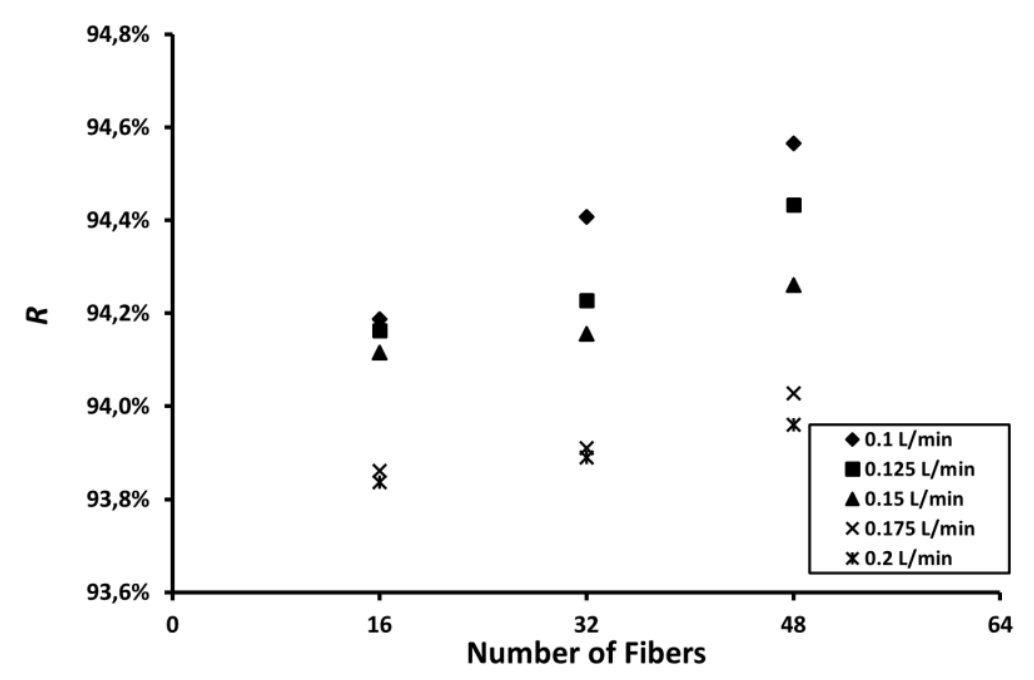

Figure 2 The $\mathrm{NO}_{\mathrm{x}}$ absorption efficiency, $R$, as a function of the number of fibers, at a feed gas flow rate, $Q_{G}$, ranging from 0.1 to $0.2 \mathrm{~L} / \mathrm{min}$

Mass transfer flux () is a parameter describing the number of moles of $\mathrm{NO}_{\mathrm{x}}$ transferred along the membrane module per area unit and time. As seen in Figure 3, the flux, J, increases as the gas flow rate increases and decreases as the number of membrane fibers increases in accordance with those expressed in Equation 4. When the gas flow rate increases, the amount of cumulative gas moving in each unit area also increases. Furthermore, an increase in the amount of $\mathrm{NO}_{\mathrm{x}}$ gas leads to an increase in the concentration between the phases, making it more of a driving force for mass transfer occurring at each of the membrane sides. Moreover, the increase in the gas flow rate reduces the number of boundary layers on the shell side of the membrane, which makes it easier for $\mathrm{NO}_{\mathrm{x}}$ to move from the gas phase to the membrane surface. Based on Equation 4, this will increase the flux, J. This finding is in accordance with the results reported by (Wang and Yu, 2017). However, with regard to the variations in the number of membrane fibers, the flux in mass transfer decreased as the number of membrane fibers increased. Thus, the packing density of the membrane is larger with respect to the thickness of the boundary layer, which is dependent on the geometry of the membrane. In the present study, the maximum mass transfer flux was $3.02 \mathrm{~mole} / \mathrm{m}^{2} \mathrm{~s}$, which was found at a gas flow rate of $0.2 \mathrm{~L} / \mathrm{min}$ using the 16 -fiber membrane. This is different from the findings reported in previous research where the maximum mass transfer flux was $4 \times 10^{-5} \mathrm{~mole} / \mathrm{m}^{2} \mathrm{~h}$ (Wang and $\mathrm{Yu}, 2017$ ).

Moreover, the mass transfer coefficient $\left(K_{L}\right)$ illustrates the effectiveness of the membrane and solvent in absorbing $\mathrm{NO}_{\mathrm{x}}$ per area unit of the module. As seen in Figure 4, the mass transfer coefficient increased as the gas flow rate increased. This is because the thickness of the boundary layer decreased as the gas flow rate increased in order to decrease the mass transfer resistance on the boundary layer in the gas phase. An increase in the number of membrane fibers resulted in a greater packing density, which led to a decrease in the mass transfer coefficient. However, the packing density affects the flow characteristics in the membrane; a higher value causes a channeling phenomenon leading to a reduction in the mass transfer coefficient as the number of membrane fibers increases. This finding is similar to the results reported in previous research where the mass transfer 
coefficient values decreased with increasing packing density or by increasing the number of membrane fibers (Kartohardjono et al., 2016).

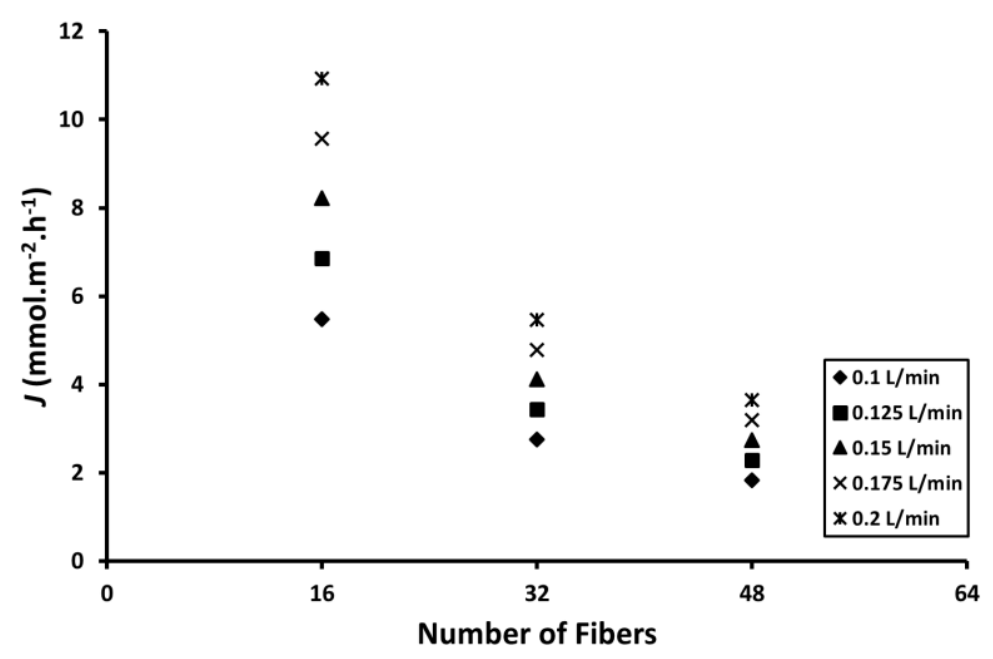

Figure 3 The mass transfer flux, $J$, as a function of the number of fibers, at a feed gas flow rate, $Q_{G}$, ranging from 0.1 to $0.2 \mathrm{~L} / \mathrm{min}$

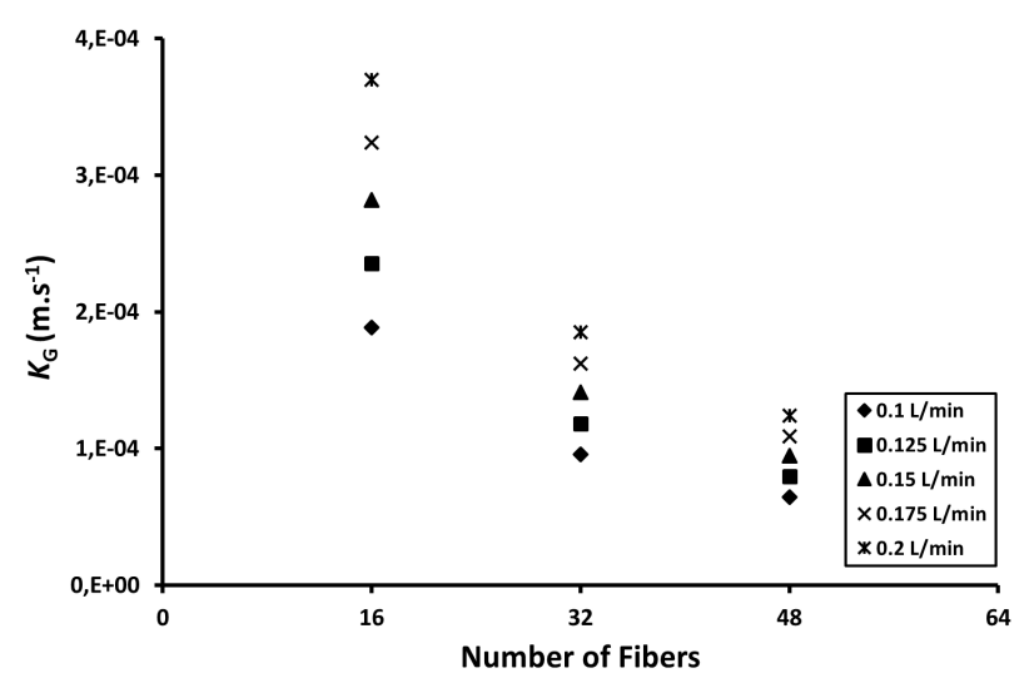

Figure 4 The mass transfer coefficent, $K_{\mathrm{G}}$, as a function of the number of fibers, at a feed gas flow rate, $Q_{G}$, ranging from 0.1 to $0.2 \mathrm{~L} / \mathrm{min}$

$\mathrm{NO}_{\mathrm{x}}$ loading is a parameter that describes the number of moles of $\mathrm{NO}_{\mathrm{x}}$ to be absorbed per unit time per unit of mole of $\mathrm{H}_{2} \mathrm{O}_{2}$ in the absorbent solution. As seen in Figure $5, \mathrm{NO}_{\mathrm{x}}$ loading increased as the feed gas flow rate increased for the membrane modules with the same number of fibers, but it was relatively constant as the number of fibers in the membrane modules increased at the same feed gas flow rate. With the addition of the gas flow rate, an increase in the concentration gradient and a decrease in the boundary layer was observed. This led to a more complete mass transfer and an increase in the overall number of moles of $\mathrm{NO}_{\mathrm{x}}$ that were transferrable. Furthermore, reducing the thickness of the boundary layer caused more $\mathrm{NO}_{\mathrm{x}}$ to be absorbed into the solvent thereby increasing the $\mathrm{NO}_{\mathrm{x}}$ loading by increasing the feed gas flow rate (Figure 5). As the number of membrane fibers increased, the area of the effective contact between the phases also increased. The addition of the contact area increased the solvent's ability to absorb $\mathrm{NO}_{\mathrm{x}}$. Therefore, with the same number of solvent moles, the solvent has the ability to absorb more $\mathrm{NO}_{\mathrm{x}}$ due to the 
increasing contact between the solvent and the gas. However, the increase in the amount of absorbed $\mathrm{NO}_{\mathrm{x}}$ was not significant because, at the feed gas flow rate applied, the efficiency was already high $(>90 \%)$ so only a small amount of $\mathrm{NO}_{\mathrm{x}}$ can be absorbed further. Consequently, the $\mathrm{NO}_{\mathrm{x}}$ loading was relatively constant as the number of fibers in the membrane modules increased (Figure 5).

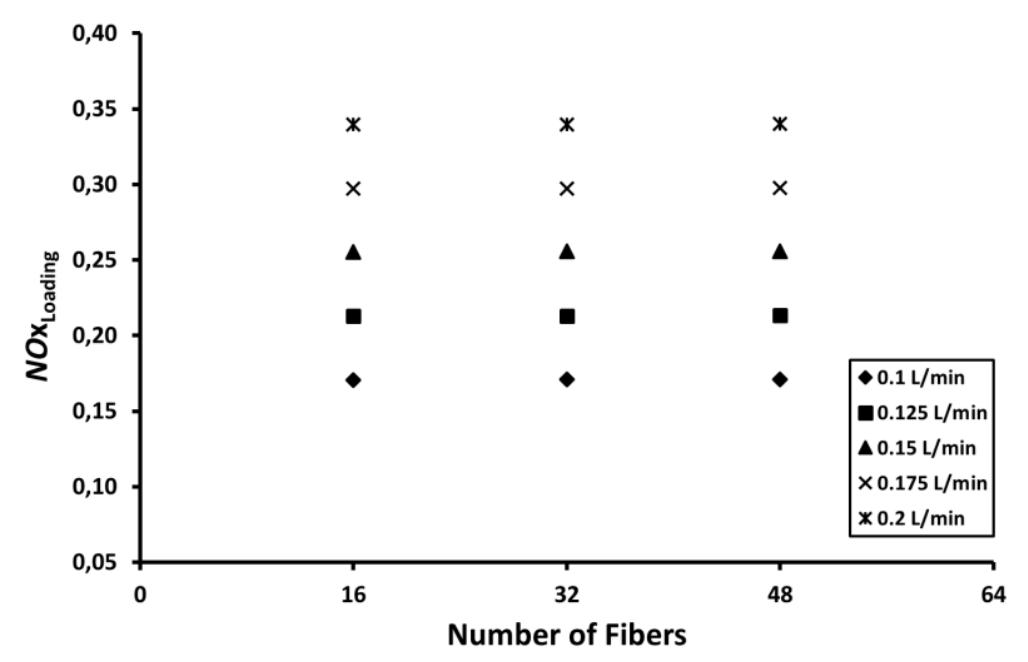

Figure $5 \mathrm{NO}_{\mathrm{x}}$ loading $\left(\left(\mathrm{mmol} \mathrm{NO} \mathrm{x}_{\mathrm{x}} / \mathrm{mol} \mathrm{H}_{2} \mathrm{O}_{2}\right) / \mathrm{h}\right)$, as a function of the number of fibers, at a feed gas flow rate, $Q_{G}$, ranging from 0.1 to $0.2 \mathrm{~L} / \mathrm{min}$

\section{Conclusions}

This study utilized hollow fiber membrane modules to absorb $\mathrm{NO}_{\mathrm{x}}$ using a mixture of $\mathrm{HNO}_{3} 0.5 \mathrm{M}$ and $\mathrm{H}_{2} \mathrm{O}_{2} 0.5 \% \mathrm{w} / \mathrm{t}$ as the absorbent. The feed gas flow rate and the number of membrane fibers were the main variables used in this study. The aim was to understand their effects on the overall mass transfer coefficient, flux, absorption efficiency, and $\mathrm{NO}_{\mathrm{x}}$ loading. The experimental results showed that the mass transfer coefficient, flux, and $\mathrm{NO}_{\mathrm{x}}$ loading increased by increasing the feed gas flow rate, while the absorption efficiency decreased. The highest $\mathrm{NO}_{\mathrm{x}}$ absorption efficiency achieved in this study was $94.6 \%$ at the feed gas flow rate of $0.2 \mathrm{~L} / \mathrm{min}$ with the membrane module with 48 fibers in the contactor. Moreover, the mass transfer coefficient and flux decreased while the absorption efficiency increased as the number of fibers in the contactor increased at the same feed gas flow rate. The $\mathrm{NO}_{\mathrm{x}}$ loading was relatively constant as the number of fibers in the contactor increased at the same feed gas flow rate. In this study, the increase in the efficiency of $\mathrm{NO}_{\mathrm{x}}$ absorption was insignificant when the amount of fibers in the membrane module increased from 16 to 42 at the feed gas flow rate of $0.1 \mathrm{~L} / \mathrm{min}$. However, the $\mathrm{NO}_{\mathrm{x}}$ absorption efficiency decrease was insignificant if the gas flow rate increased from 0.1 to $0.2 \mathrm{~L} / \mathrm{min}$ on a membrane module with 48 fibers. The $\mathrm{NO}_{\mathrm{x}}$ absorption efficiency achieved in this study was already high (about 93.8\%), even for the membrane module with the lowest number of fibers (16 fibers) and at the highest feed gas flow rate $(0.2 \mathrm{~L} / \mathrm{min})$.

\section{Acknowledgements}

The authors wish to acknowledge that they received financial support for this study from the PDUPT Project via Directorate of Research and Services Universitas Indonesia through Contract No. NKB-1665/UN2.R3.1/HKP.05.00/ 2019. 


\section{References}

Adewuyi, Y.G., Khan, M.A., Sakyi, N.Y., 2014. Kinetics and Modeling of the Removal of Nitric Oxide by Aqueous Sodium Persulfate Simultaneously Activated by Temperature and $\mathrm{Fe}^{2+}$. Industrial \& Engineering Chemistry Research, Volume 53(2), pp. 828-839

Anggraini, I.D., Keryanti., Kresnowati, M.T.A.P., Purwadi, R., Noda, R., Watanabe, T., Setiadi, T., 2019. Bioethanol Production via Syngas Fermentation of Clostridium Ljungdahlii in a Hollow Fiber Membrane Supported Bioreactor. International Journal of Technology, Volume 10(3), pp. 481-490

Choi, J., Lee, K.S., Choi, D.Y., Kim, Y.J., Kim, S.S., 2014. Dry De-NO ${ }_{x}$ Process via Gas-phase Photochemical Oxidation using an Ultraviolet and Aerosolized $\mathrm{H}_{2} \mathrm{O} / \mathrm{H}_{2} \mathrm{O}_{2}$ Hybrid System. Energy \& Fuels, Volume 28(8), pp. 5270-5276

Gao, L., Li, C., Lu, P., Zhang, J., Du, X., Li, S., Zeng, G., 2018. Simultaneous Removal of HgO and NO from Simulated Flue Gas Over Columnar Activated Coke Granules Loaded with $\mathrm{La}_{2} \mathrm{O}_{3}-\mathrm{CeO}_{2}$ at Low Temperature. Fuel, Volume 215, pp. 30-39

Indonesia, P.R., 1999. Peraturan Pemerintah No. 41 Tahun 1999 Tentang: Pengendalian Pencemaran Udara. (Air Pollution Control No. 41), pp. 1-34

Kartohardjono, S., Darmawan, R., Karyadi, M.F., Saksono, N., 2016. $\mathrm{CO}_{2}$ Absorption through Super-hydrophobic Hollow Fiber Membrane Contactors. Journal of Environmental Science and Technology, Volume 9(2), pp. 214-219

Kartohardjono, S., Merry, C., Rizky, M.S., Pratita, C.C., 2019a. Nitrogen Oxide Reduction through Absorbent Solutions Containing Nitric Acid and Hydrogen Peroxide in Hollow Fiber Membrane Modules. Heliyon, Volume 5(12), pp. 1-10

Kartohardjono, S., Paramitha, A., Putri, A.A., Andriant, R., 2017. Effects of Absorbent Flow Rate on $\mathrm{CO}_{2}$ Absorption through a Super Hydrophobic Hollow Fiber Membrane Contactor. International Journal of Technology, Volume 8(8), pp. 1429-1435

Kartohardjono, S., Saksono, N., Supramono, D., Prawati, P., 2019b. NO 2 Removal from Air through Super Hydrophobic Hollow Fiber Membrane Contactors. International Journal of Technology, Volume 10(3), pp. 472-480

Kartohardjono, S., Shabanindita, S., Harianja, M., Dixon, A.O., Yuliusman, Y., Saksono, N. 2019c. $\mathrm{N}_{2} \mathrm{O}$ Absorption through Super Hydrophobic Hollow Fiber Membrane Contactor. Environmental Progress and Sustainable Energy, Volume 38(2), pp. 362-366

Kumar, A.P.M., Sreekumar, J.S., Mohanan, P., 2015. The Effect of Cordierite/Pt Catalyst on the $\mathrm{NO}_{\mathrm{x}}$ Reduction in a Diesel and Jatropha Bio-diesel Operated Single Cylinder Engine. Journal of Environmental Chemical Engineering, Volume 3(2), pp. 1125-1136

Lipnizki, F., Field, R.W., 2001. Mass Transfer Performance for Hollow Fibre Modules with Shell-side Axial Feed Flow: Using an Engineering Approach to Develop a Framework. Journal of Membrane Science, Volume 193(2), pp. 195-208

Shaikh, A., Al-Dahhan, M., 2013. Scale-up of Bubble Column Reactors: A Review of Current State-of-the-Art. Industrial \& Engineering Chemistry Research, Volume 52(24), pp. 8091-8108

Sun, P., Cheng, X., Wang, Z., Lai, Y., Ma, C., Chang, J., 2019. NO $_{\mathrm{x}}$ Reduction by CO Over ASC Catalysts in a Simulated Rotary Reactor: Effect of Reaction Conditions. Journal of the Energy Institute, Volume 92(3), pp. 488-501

Wang, Y., Yu, X., 2017. Removal of NO Research in a Polypropylene Hollow Fiber Membrane Contactor. In: The $6^{\text {th }}$ International Conference on Energy, Environment and Sustainable Development (ICEESD 2017)

Wang, Z., Zhang, Y., Tan, Z., Li, Q., 2018. A Wet Process for Oxidation-Absorption of Nitric Oxide by Persulfate/Calcium Peroxide. Chemical Engineering Journal, Volume 350, pp. 767-775 
Xia, L., Law, A.W.-K., Fane, A.G., 2013. Hydrodynamic Effects of Air Sparging on Hollow Fiber Membranes in a Bubble Column Reactor. Water research, Volume 47(11), pp. 3762-3772 